\title{
Experimental Observations of Frictional Heating in Fiber-Reinforced Ceramics
}

\author{
John W. Holmes* and Chongdu Cho* \\ Ceramic Composites Research Laboratory, Department of Mechanical Engineering and Applied Mechanics,
} The University of Michigan, Ann Arbor, Michigan 48109-2125

\begin{abstract}
The influence of fatigue loading history and microstructural damage on the magnitude of frictional heating and interfacial shear stress in a unidirectional $\mathrm{SiC}$ fiber/calcium aluminosilicate matrix composite was investigated. The extent of frictional heating was found to depend upon loading frequency, stress range, and average matrix crack spacing. The temperature rise attained during fatigue can be significant. For example, the temperature rise exceeded $100 \mathrm{~K}$ during fatigue at $75 \mathrm{~Hz}$ between stress limits of 220 and $10 \mathrm{MPa}$. Analysis of the frictional heating data indicates that the interfacial shear stress undergoes an initially rapid decrease during the initial stages of fatigue loading: from an initial value over $20 \mathrm{MPa}$, to approximately $5 \mathrm{MPa}$ after $25000 \mathrm{cy}$ cles. Over the range of 5 to $25 \mathrm{~Hz}$, the interfacial shear stress was not significantly influenced by loading frequency. The implications of frictional heating in fiber-reinforced ceramics are also discussed. [Key words: composites, ceramics, fatigue, interfaces, shear.]
\end{abstract}

\section{Introduction}

D URING cyclic loading, considerable hysteresis in the stressstrain response of fiber-reinforced ceramics is commonly observed at ambient and elevated temperatures. ${ }^{1-5}$ This hysteresis, which is a measure of the energy dissipation during a fatigue cycle, is related to the frictional slip of fibers along debonded interfacial slip zones. ${ }^{6-9}$ The repeated frictional sliding of fibers can give rise to very substantial internal heating during the cyclic loading of fiber-reinforced ccramics., ${ }^{5,10,11}$ For example, a temperature rise of $30 \mathrm{~K}$ was observed during the room-temperature fatigue of cross-ply $\mathrm{C}_{\mathrm{f}} / \mathrm{SiC}$ composites at $85 \mathrm{~Hz}$ between stress limits of 250 and $10 \mathrm{MPa} .^{10} \mathrm{~A}$ more dramatic temperature rise of $50 \mathrm{~K}$ has been measured during the fatigue of unidirectional $\mathrm{SiC}$ fiber/calcium aluminosilicate matrix composites at $25 \mathrm{~Hz}$ between stress limits of 240 and $10 \mathrm{MPa} .1$

The occurrence of frictional heating in ceramic-matrix composites is of both practical and fundamental significance. From a practical viewpoint, fiber-reinforced ceramics are under development for use in advanced gas-turbines, heat exchangers, and space-based structures. For these applications, a temperature rise caused by frictional heating could result in unacceptable dimensional changes, as well as changes in the mechanical behavior and thermophysical propertics of the composite. From a fundamental viewpoint, the temperature increase which occurs during fatigue could alter the interfacial shear stress in a composite (through differential thermal ex-

D. B. Marshall-contributing editor

Manuscript No. 196683. Received May 21, 1991; approved December $20,1991$.

Supported by the Air Force Office of Scicntific Research under Grant No. 91-0106.

*Member, American Ceramic Society. pansion between the fiber and matrix), leading to a frequency dependence of mechanical behavior, including toughness, strength, modulus, fatigue life, and mechanical damping. It is also possible that differential thermal expansion between the fiber and matrix could cause the further extension of initial interfacial debonding. As a consequence of the low thermal conductivity of many ceramic matrices, the local temperature rise in the vicinity of the fiber/matrix interface may be significantly higher than the bulk temperature rise. Independent of the operating temperature of a component or structure, a further temperature increase at the interface (by frictional heating) could result in an increased rate of chemical diffusion near the fiber/matrix interface. For applications where energy dissipation is desired, frictional heating could be an asset, since it provides a potent mechanism for the dissipation of mechanical energy during monotonic and cyclic loading.

The present paper builds upon an earlier experimental investigation of frictional heating in $\mathrm{SiC}$ fiber/calcium aluminosilicate composites (hereafter referred to as Nicalon/CAS-II)* which established a correlation between the initiation of matrix cracking and the onset of frictional heating. " Specifically, this paper examines the relationship between stress range, loading frequency, and matrix crack spacing on the magnitude of frictional heating and the change in interfacial shear stress which occurs during the fatigue of Nicalon/CAS-II composites.

\section{Experimental Procedure}

A 16-ply unidirectional Nicalon/CAS-II calcium aluminosilicate matrix composite was used in this investigation. The composite, formed by hot-pressing into rectangular billets, had a nominal fiber content of $35 \mathrm{vol} \%$. Edge-loaded tensile specimens with a $33-\mathrm{mm}$ gage length (see Fig, 1) were machined from the billet using diamond tooling. Specimens were removed from the billet such that the reinforcing fibers were parallel to the tensile loading axis. An optical micrograph showing the typical fibcr distribution in the specimens is shown in Fig. 2. The minor faces of the specimen gage section were polished with diamond paste to a $0.1-\mu \mathrm{m}$ finish to allow acetate-film replicas of surface cracking to be obtained.

Monotonic tension and tension-tension fatigue testing was conducted on an MTS Model 810 servohydraulic load-frame (MTS Systems Corp., Minneapolis, MN) equipped with edgeloaded grips. Details of the gripping arrangement and typical bending strains have been discussed elsewhere. ${ }^{12}$ A watercooled test chamber, which completely surrounded the specimen and grips (see Fig. 3), was used to maintain the air temperature in the vicinity of the specimen at $293 \pm 0.1 \mathrm{~K}$. The relative humidity within the chamber was between $65 \%$ and $67 \%$. Gage-section strains were measured using a clip-on extensometer (Model No. 632.27B-20, MTS Systems Corp.; modified for a 33- $\mathrm{mm}$ gage length). The extensometer was

${ }^{*}$ Composites processed by Corning Inc., Corning, NY. Nicalon is the designation for SiC fibers produced by Nippon Carbon. Tokyo, Japan. CAS-Il is ihe Corning designation for the calcium aluminosilicate matrix used in this composite system. 


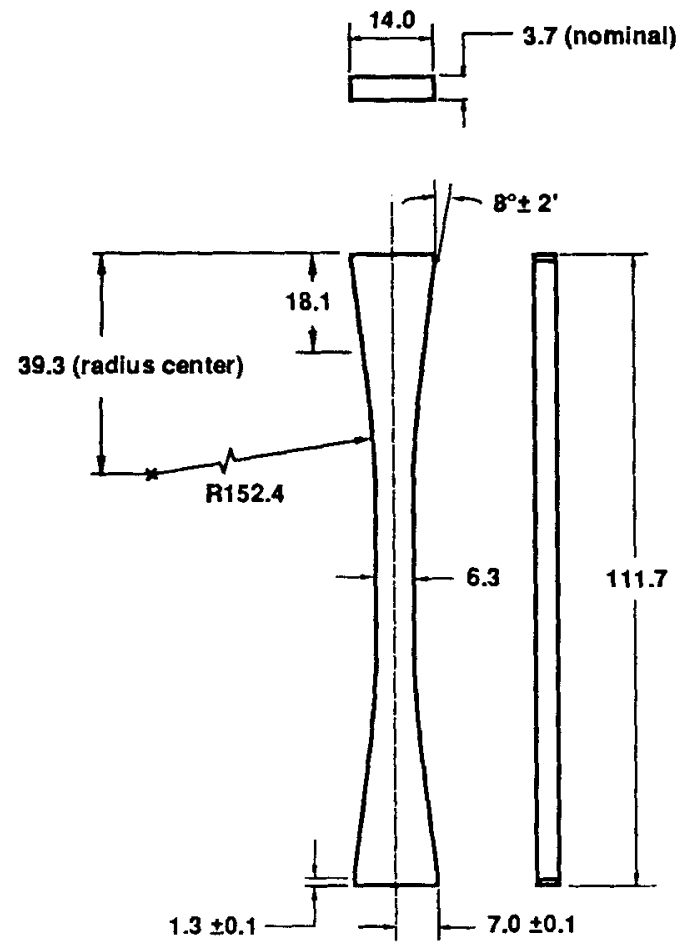

Fig. 1. Specimen geometry used to investigate frictional heating in ceramic-matrix composites. Dimensions given in millimeters.

mounted along one of the specimen edges (Fig. 3). Extensometer and load-cell signals were gathered using a high-speed 16-bit resolution data acquisition system (Model MBC-625, GW Instruments, Sommerville, MA; with 16-bit, $50-\mathrm{kHz}$ daughterboards). During the fatigue experiments, the specimen temperature was measured with an infrared pyrometer which was focused at the center of the specimen gage section to a diameter of $5 \mathrm{~mm}$ (Model No. 5402, Everest Interscience Inc., Fullerton, CA). The pyrometer had a resolution (background noise level) of $0.1 \mathrm{~K}$ and a response time of $300 \mathrm{~ms}$. The pyrometer data were collected by a separate 16bit resolution data acquisition system (Model No. ACM2-16, Strawberry Tree Computers, Sunnyvale, CA). The temperature within the isothermal test chamber was allowed to equilibrate for $5 \mathrm{~h}$ prior to starting the fatigue experiments. Monotonic tensile tests and the initial loading ramps used in the fatigue experiments were conducted at a constant loading rate of $100 \mathrm{MPa} / \mathrm{s}$. A rapid loading rate was used to

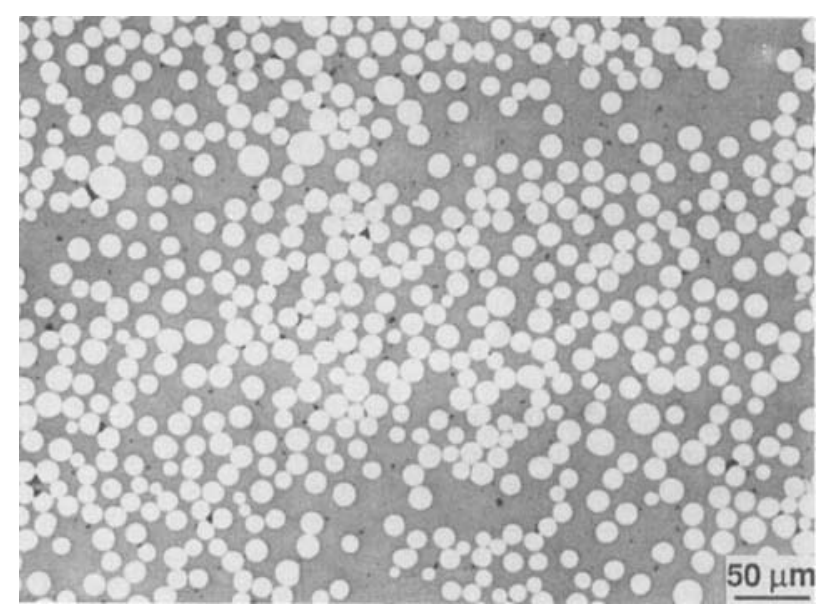

Fig. 2. Optical micrograph showing typical fiber distribution in the $[0]_{1}-$ Nicalon/CAS-II specimens. The composite had a nominal fiber fraction of $35 \mathrm{vol} \%$

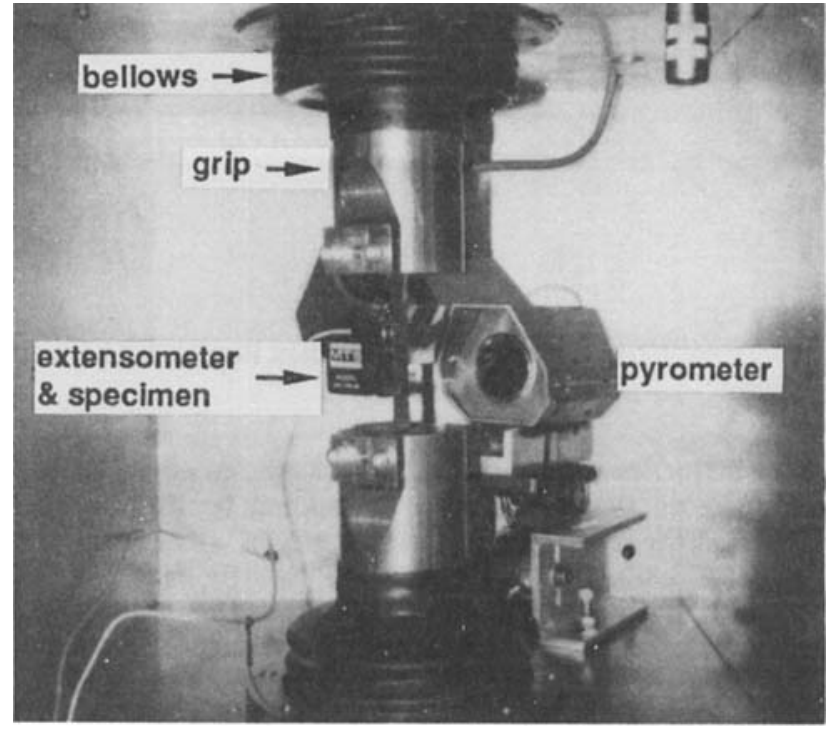

Fig. 3. Experimental arrangement used to investigate frictional heating in fiber-reinforced ceramics. The isothermal test chamber, which completely surrounded the specimen and grips, had a volume of $0.025 \mathrm{~m}^{3}$. The temperature within the chamber was controlled to $293 \pm 0.1 \mathrm{~K}$ by circulating water through the chamber walls.

prevent time-dependent matrix cracking. ${ }^{\dagger}$ All fatigue experiments were performed under load control using a sinusoidal waveform.

The fatigue tests were periodically interrupted to obtain surface replicas of matrix crack spacing; a stress of $10 \mathrm{MPa}$ was maintained on the specimen while taking the replicas. Although crack definition could be improved slightly by increasing the tensile stress at which the replicas were taken, the use of a higher stress (e.g., $50 \mathrm{MPa}$ ) was found to cause time-dependent matrix cracking within the 5 min required to obtain a replica. Time-dependent cracking; was observed only during the initial stages of fatigue-pricr to the establishment of a stable crack density. Surface replicas were obtained from only one of the specimen edges (the location of the extensometer prevented taking replicas along both edges). However, results obtained from several trial experiments conducted without the extensometer showed that the average crack spacing along the two edges typically differed by only 2 to $4 \mu \mathrm{m}$. Moreover, these trial experiments showed essentially identical results when measurements of crack spacing were made along the broad faces of the gage section. To obtain confidence in the data trends, at least 140 crack pairs were measured. Using optical and scanning electron microscopy of the surface replicas, the average crack spacing could be confidently determined to within $\pm 2.0 \mu \mathrm{m}$.

\section{Results and Discussion}

\section{(1) Tensile Behavior}

The monotonic tensile behavior of the Nicalon/CAS-II composite at $293 \mathrm{~K}$ is shown in Fig. 4. The initial deviation from linear behavior occurred at approximat sly $225 \mathrm{MPa}$; using notation introduced by Prewo and co-workers ${ }^{2,3}$ this stress level will be referred to as the proportional limit strength, $\sigma_{\mathrm{pl}}$. The proportional limit corresporids to the occurrence of a mechanically detectable amount of matrix or fiber damage. When defined in this manner, the value as-

\footnotetext{
"Unpublished work by the authors has shown that time-cependent matrix cracking at room temperature can significantly influence the proportional limit stress, ultimate strength, and overall shape of the monotonic stress strain curve for fiber-reinforced ceramics. This effect is most apparent when loading rates below $10 \mathrm{MPa} / \mathrm{s}$ are used: for most ceramic cormposites, loading rates of 50 to $500 \mathrm{MPa} / \mathrm{s}$ give essentially identical stress-st rain curves.
} 


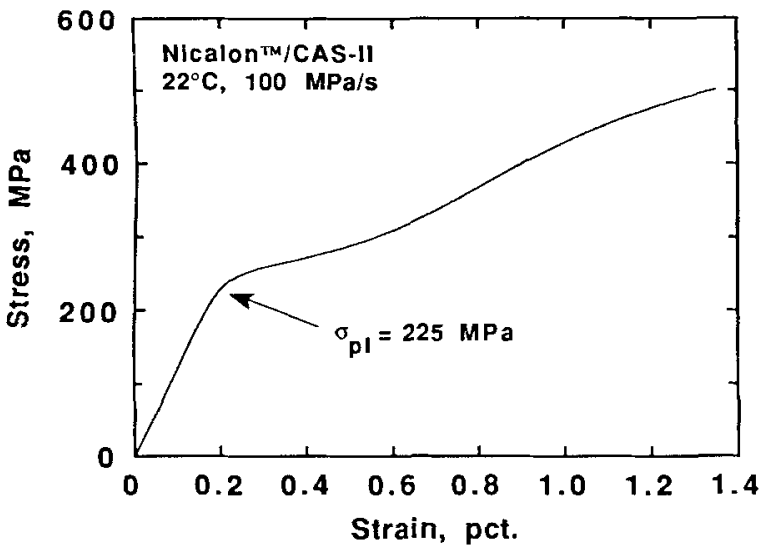

Fig. 4. Monotonic tensile behavior of $[0]_{16}$-Nicalon/CAS-II at $293 \mathrm{~K}$. To avoid time-dependent matrix cracking, the specimens were loaded at a rate of $100 \mathrm{MPa} / \mathrm{s}$.

signed to the proportional limit strength is influenced by the sensitivity of the extensometer and load cell, as well as the loading or displacement rate used during monotonic loading. As discussed below, during fatigue, matrix cracking was first observed at a peak stress of $120 \mathrm{MPa}$, which is approximately $50 \%$ below the monotonic proportional limit strength measured with virgin specimens.

\section{(2) Initiation of Frictional Heating}

Although discussed in detail elsewhere, ${ }^{11}$ it is convenient to briefly review recent expcrimental results which showed that the onset of frictional heating during cyclic loading coincides with the initiation of matrix cracking. To establish this correlation, an experiment was conducted wherein the peak fatigue stress was increased in 20-MPa steps from 100 to $240 \mathrm{MPa}$. During this experiment, which was conducted at a sinusoidal loading frequency of $25 \mathrm{~Hz}$, the minimum fatigue stress was held constant at $10 \mathrm{MPa}$. The specimen was fatigued for 25000 cycles at cach peak stress. The initiation of matrix cracking, and subsequent change in crack spacing as the peak stress was increased, was determined by taking surface replicas after the first fatigue cycle and at the completion of each 25000 cycle fatigue loading block.

Based upon two test results, neither a temperature rise nor matrix cracking was observed at $100 \mathrm{MPa}$. Coinciding with the formation of several matrix cracks, a temperature rise of $0.3 \mathrm{~K}$ to $0.4 \mathrm{~K}$ was measured at a peak fatigue stress of $120 \mathrm{MPa}$. As mentioned earlier, this stress is approximately $50 \%$ below the monotonic proportional limit strength of the composite. Noting that interfacial debonding and the formation of intcrfacial slip zones typically accompany matrix cracking, this result provided experimental confirmation that the frictional sliding of fibers is responsible for the internal heating which occurs in fiber-reinforced ceramics. The experiment was continued at higher peak stresses to investigate the relationship between maximum temperature rise, stress range, and mean crack spacing. The temperature rise curves are shown in Fig. 5. As shown in Fig. 6, the average matrix crack spacing approached an approximate plateau between peak stresses of 200 and $240 \mathrm{MPa}$. For a constant crack spacing, the roughly $25 \mathrm{~K}$ temperature rise between 200 and $240 \mathrm{MPa}$ is higher than the temperature rise which would be expected based solely on an increase in stress range (see later discussion). Thus, other factors, such as the occurrence of additional fiber fractures and an increase in the debond length of fibers, contribute to the temperature rise.

In the experiments described above, no attempt was made to separate the influence of peak fatigue stress, stress range, and matrix crack spacing on the extent of frictional heating. The remainder of this paper discusses experiments which were performed in an attempt to isolate the effect of these variables. Whenever possible, the expcrimental trends were

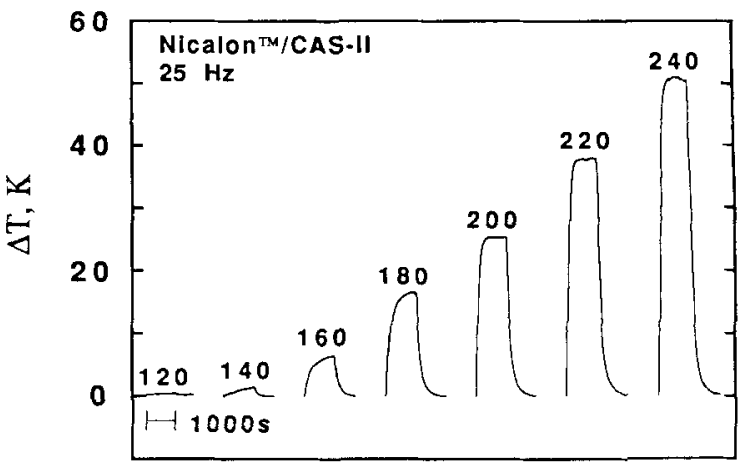

Fig. 5. Influence of stress range on temperature rise. Fixing the minimum fatigue stress at $10 \mathrm{MPa}$, the maximum fatigue stress was increased in $20-\mathrm{MPa}$ increments from 100 to $240 \mathrm{MPa}$. The specimen was fatigued for $1000 \mathrm{~s}$ at each stress level. Coinciding with the initiation of matrix cracking, a temperature rise of $0.3 \mathrm{~K}$ was first detected at a stress of $120 \mathrm{MPa}$. The initial temperature of the composite was 293 K. From Holmes and Cho.

established using a single specimen, thus avoiding potential errors in the interpretation of the experimental results that could arise from slight variations in fiber distribution and volume fraction between specimens.

\section{(3) Influence of Stress Range and Peak Fatigue Stress on Frictional Heating}

Trial experiments had shown that once a constant crack density was achieved at a given peak stress, fatigue at peak stresses equal to or below this stress would not alter the crack spacing. Thus, to determine the influence of peak fatigue stress and stress range on temperature rise at a fixed crack spacing, a series of constant stress range experiments were conducted using a specimen which was initially "prefatigued" for 100000 cycles at $25 \mathrm{~Hz}$ between fixcd stress limits of 180 and $10 \mathrm{MPa}$. Next, an experiment was conducted wherein the stress range was held constant, while the peak fatigue stress was sequentially increased in $20-\mathrm{MPa}$ steps up to the initial prefatigue stress of $180 \mathrm{MPa}$. Using the same specimen, this experiment was performed at stress ranges of 90,110 , and $130 \mathrm{MPa}$. The specimen was fatigued for 25000 cycles for each combination of peak stress and stress range. A schematic of the loading history is shown in Fig. 7.

During prefatigue at $180 \mathrm{MPa}$, the specimen was pcriodically unloaded to $10 \mathrm{MPa}$ to allow measurement of the matrix crack spacing. From these measurements, the mean crack spacing approached a constant value of $198 \mu \mathrm{m}$ within 20000 cycles (see Fig. 8). After an initially rapid decay, the

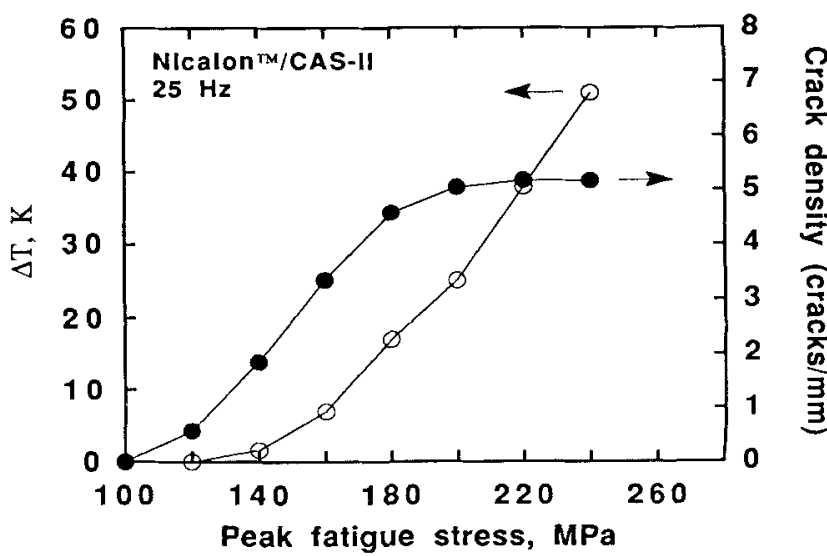

Fig. 6. Temperature rise and matrix crack density (reciprocal of mean crack spacing) vs maximum fatigue stress. The crack density reached an approximate plateau above $200 \mathrm{MPa}$. For all loading histories, the loading frequency was $25 \mathrm{~Hz}$ and the minimum fatigue stress was $10 \mathrm{MPa}$. The initial temperature of the composite was $293 \mathrm{~K}$. After Holmes and Cho." 


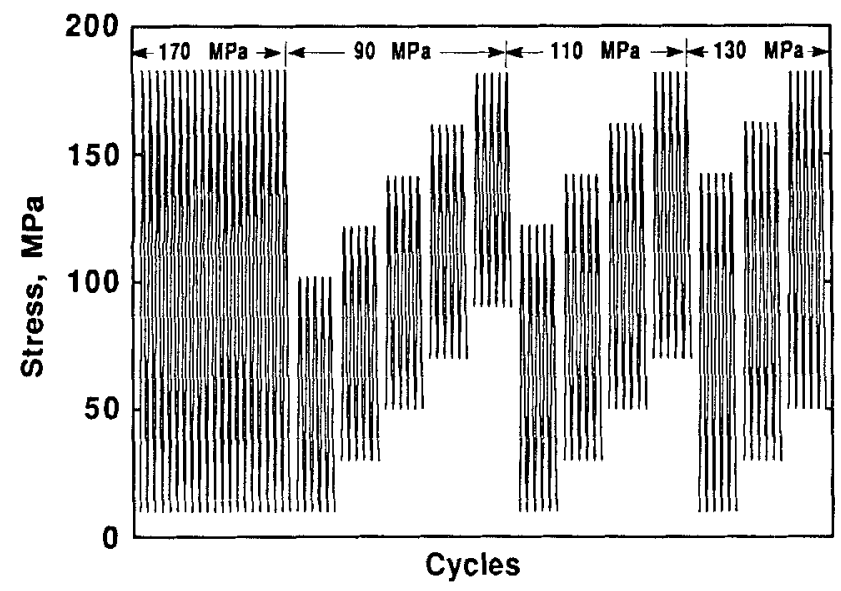

Fig. 7. Loading history used to investigate the influence of stress range $(\Delta \sigma)$ and maximum fatigue stress on temperature rise. To achieve a constant crack density, the specimen was first prefatigued for 100000 cycles at $25 \mathrm{~Hz}$ between fixed stress limits of 180 and $10 \mathrm{MPa}$. Each constant-stress-range experiment was conducted for 25000 cycles at a loading frequency of $25 \mathrm{~Hz}$. The stress range is given above each group of fatigue loading blocks.

cyclic stress-strain modulus approached an approximate plateau within 50000 cycles. The initial decrease in modulus is attributed to matrix cracking and interfacial debonding. The lag in stabilization of the cyclic stress-strain modulus, which occurred at a slower rate than stabilization of the crack spacing, is attributed to additional interfacial debonding which would continue to occur even after a constant crack spacing was achieved. A slight $(<2 \%)$ recovery in modulus was observed between approximately 75000 and $100000 \mathrm{cy}$ cles; as discussed later, a further recovery in modulus occurs during longer-duration fatigue experiments. A similar modulus recovery has been observed in unidirectional Nicalon/ aluminosilicate composites, ${ }^{13} 3-\mathrm{D}$ braided $\mathrm{SiC}_{t} / \mathrm{SiC}^{1,3}$ and $0^{\circ} / 90^{\circ} \mathrm{C}_{\mathrm{f}} / \mathrm{SiC}^{5}$

The matrix crack spacing was measured at the completion of each 25000 -cycle loading block used in the constant stress range experiments; the matrix crack spacing remained essentially constant at $198 \mu \mathrm{m}$ (as mentioned earlier, the crack spacing remains constant so long as the prefatigue stress is not exceeded). As shown in Fig. 9(A), the maximum temperature rise exhibited an approximately linear dependence on stress range; a $20-\mathrm{MPa}$ increase in stress range resulted in an average temperature increase of $3.2 \mathrm{~K}$. In contrast to the marked sensitivity to stress range, the temperature rise showed only a weak dependence on peak fatigue stress. For example, at a stress range of $90 \mathrm{MPa}$, the temperature rise varied by less

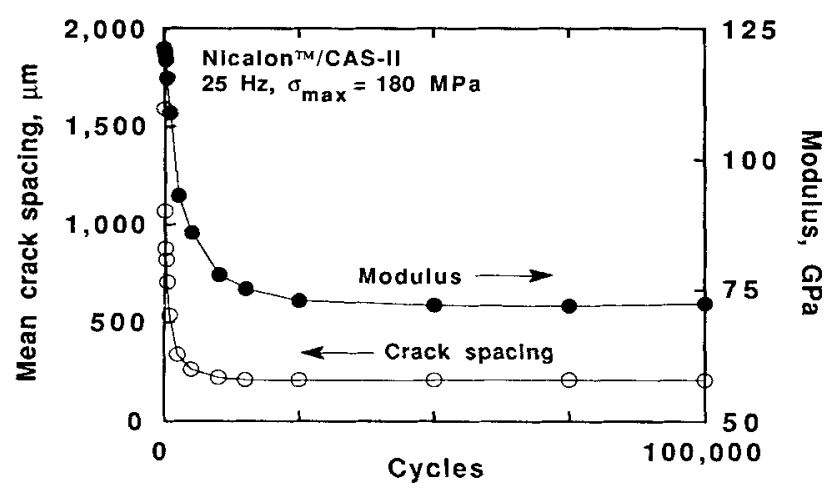

Fig. 8. Change in matrix crack spacing and cyclic stress-strain modulus during fatigue at $25 \mathrm{~Hz}$ between fixed stress limits of 180 and $10 \mathrm{MPa}$. Note that a stable crack density was achieved within approximately 20000 cycles. For this loading history, the modulus reached an approximate plateau between approximately 25000 and 30000 cycles.

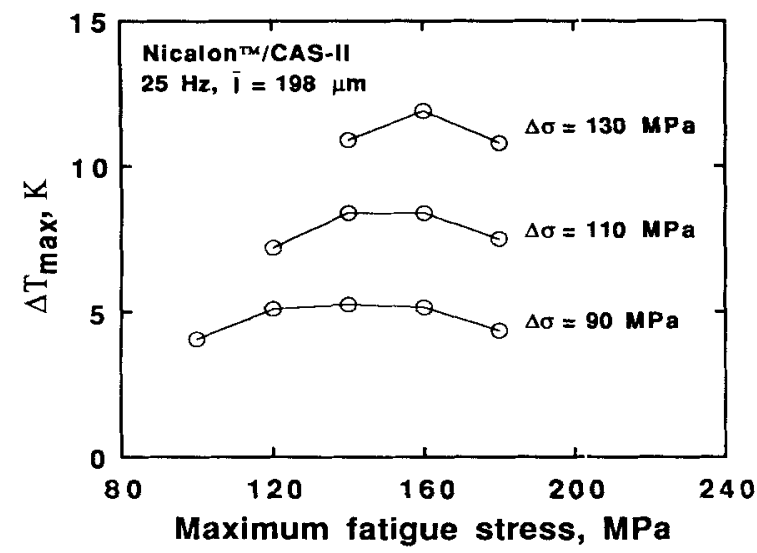

(A)

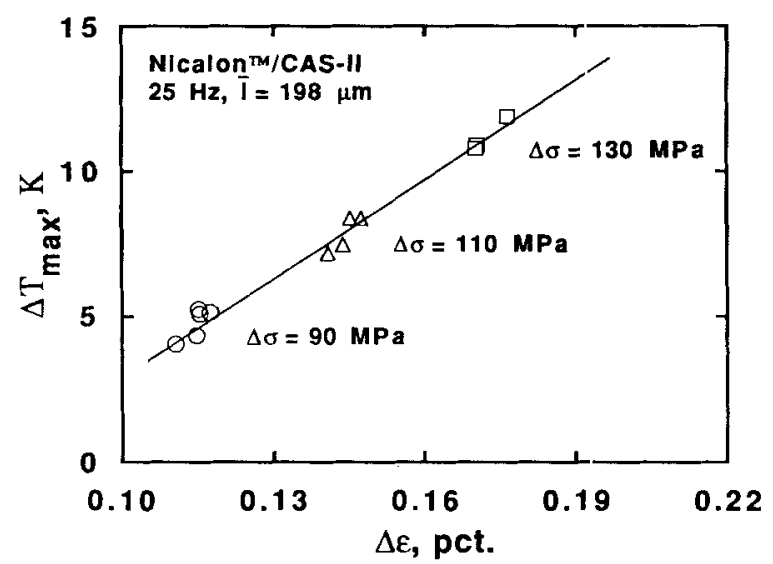

(B)

Fig. 9. (A) Influence of stress range $(\Delta \sigma)$ and maximum fatigue stress on temperature rise. For a given stress rarge, the temperature rise exhibits a weak dependence on peak fatigue stress. (B) Relationship between maximum temperature rise and strain range. The approximately linear relationship between temperature rise and strain range suggests a mechanism of internal heating involving the frictional slip of fibers. The loading history is shown in Fig. 7.

than $1 \mathrm{~K}$ when the peak stress was increased by $80 \mathrm{MPa}$ (sce Fig. 9(A)). When the maximum temperature rise is plotted against total strain range (Fig. 9(B)), an approximately linear relationship is found. For a constant crack sfacing, the frictional sliding distance of fibers, and hence the amount of heat energy generated, scales with the spccimen strain range Thus, the linear relationship between strain sange and temperature rise is consistent with a mechanism cf internal heating involving the repeated frictional sliding of fibers within debonded interfacial slip zones.

Examination of Fig. 9(B) shows that for a given stress range the temperature rise reached a maximum at intermediate levels of peak stress. In Fig. 10, the hysteresis curves from the experiments conducted at a constant stress range of $130 \mathrm{MPa}$ are plotted. Comparison of Figs. 9(A) and 10 shows that the peak in tempcrature rise corresponds to a peak in energy dissipation at intermediate levels of peak fatigue stress. The mechanism responsible for this peak in energy dissipation is not known at this time. It is also interesting to note that the shape and area of the hysteresis envelope formed by merging the individual hysteresis curves is approximately the same as the hysteresis curve obtained by fatiguing direc:ly between the extremes of the stress limits used in the constent stress range experiments (in this case between 180 and $19 \mathrm{MPa}$ ). Thus, once a constant crack density has been achieved at a given peak stress and stress range, for example, af ter fatigue be- 


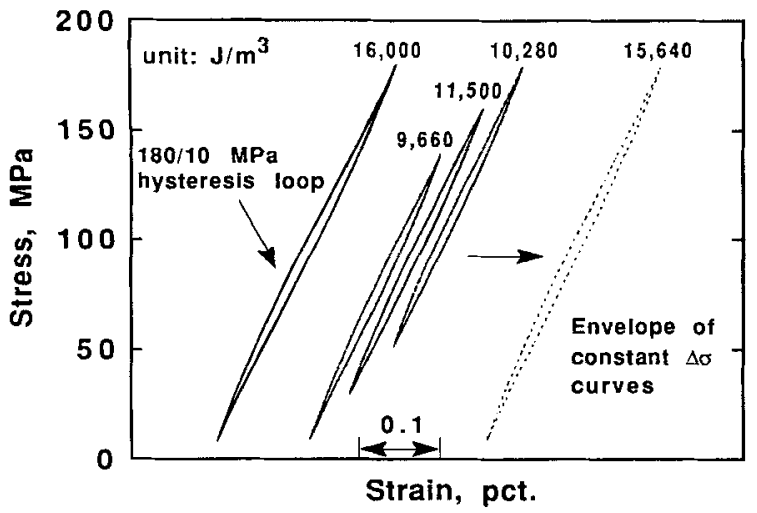

Fig. 10. Stress-strain hysteresis curves obtained after $100000 \mathrm{cy}$ cles of "prefatigue" between stress limits of 180 and $10 \mathrm{MPa}$ and during subsequent fatigue experiments conducted at a stress range of $130 \mathrm{MPa}$ (the peak stresses were 140,160 , and $180 \mathrm{MPa}$; see Fig. 7). The constant stress range curves have been separated for clarity. Corresponding to the peak in temperature rise (Fig. 9(A)), the energy dissipation was a maximum at an intermediate level of peak fatigue stress. To the right is the hysteresis envelope formed by overlaying the three constant stress range curves.

tween 180 and $10 \mathrm{MPa}$, the energy dissipation and temperature rise which would occur at lower peak stresses can be estimated from the $180 \mathrm{MPa} / 10 \mathrm{MPa}$ hysteresis curves. This approach would drastically reduce the number of experiments required to characterize the history dependence of frictional heating.

\section{(4) Influence of Crack Spacing and Test Frequency on Internal Heating}

For a mechanism of internal heating involving the frictional slip of fibers along interfacial slip zones, the amount of internal heating will depend upon the total number and length of the debonded slip zones which are present in the composite. The number of debonded zones is a function of the mean crack spacing, ${ }^{14-16}$ which, in turn, is determined by the maximum fatigue stress. Since the energy dissipation (as heat) depends upon the number of slip zones, the temperature rise should increase as the mean crack spacing decreases. To investigate the relationship between matrix crack spacing and temperature rise, the crack spacing in a specimen was sequentially decreased by prefatiguing at maximum stresses of $160,180,200$ and $220 \mathrm{MPa}$. Each prefatigue experiment was conducted for 50000 cycles, a loading frequency of $25 \mathrm{~Hz}$, and a minimum stress of $10 \mathrm{MPa}$. After prefatiguing at a given maximum stress (to achieve a stable crack spacing characteristic of the particular stress level), the specimen was sequentially fatigued at frequencies of $5,10,25,50$, and $75 \mathrm{~Hz}$ between fixed stress limits of 160 and $10 \mathrm{MPa}$ (the loading history is shown in Fig. 11). At each loading frequency, the specimen was fatigued for $1000 \mathrm{~s}$, which was sufficient for the temperature rise to attain an approximate plateau. After each 1000-s fatigue loading block, the specimen was allowed to cool to ambient temperature prior to fatiguing at the next loading frequency. The stress levels used in the prefatigue experiments provided average matrix crack spacings $\bar{l}$, which ranged from $228 \mu \mathrm{m}$ at a peak stress of $160 \mathrm{MPa}$, to $181 \mu \mathrm{m}$ at a peak stress of $220 \mathrm{MPa}$ (see Fig. 12). The average crack spacing was also measured after each 1000-s fatigue loading block to determine if the initial crack spacing changed during the variablefrequency experiments; in all cases, there was no measurable change in crack spacing.

Typical temperature rise curves obtained during the variable-frequency fatigue experiments are shown in Fig. 13. The maximum temperature rise is plotted in Fig. 14(A), as a function of mean crack spacing and loading frequency. At a given frequency the maximum temperature rise increased as the crack spacing decreased. This is to be expected; as the crack spacing decreases, the total number of interfacial slip

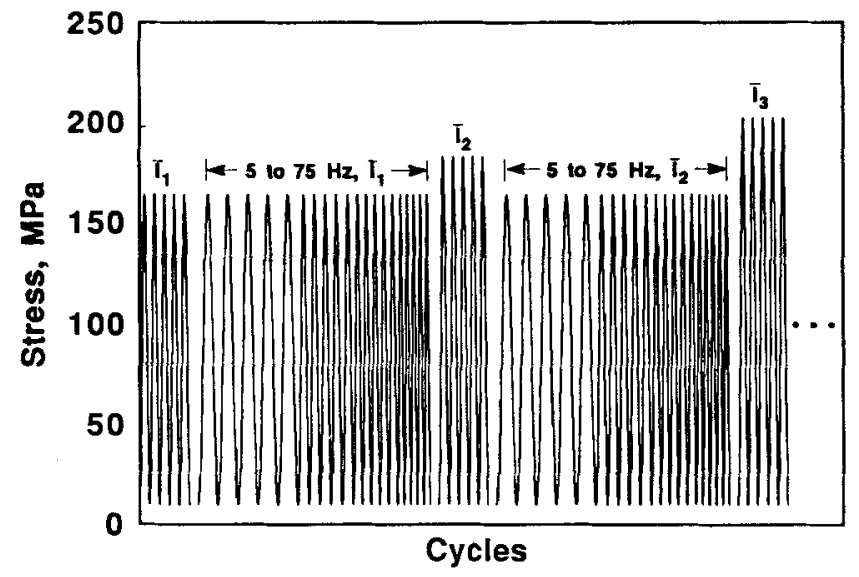

Fig. 11. Loading sequence used to investigate the influence of test frequency and matrix crack spacing on temperature rise. To change the crack spacing, the maximum fatigue stress was sequentially increased; maximum stresses of $160,180,200$, and $220 \mathrm{MPa}$ were employed (at each stress, the crack spacing was stabilized by fatiguing for 50000 cycles at $25 \mathrm{~Hz}$; the minimum cycle stress was $10 \mathrm{MPa}$ ). For each crack spacing, the specimen was sequentially subjected to fatigue at loading frequencies of $5,10,25,50$, and $75 \mathrm{~Hz}$; the specimen was fatigued for $1000 \mathrm{~s}$ at each frequency.

zones present in the specimen increases, providing additional sites for heat generation by frictional slip. The inverse relationship between temperature rise and average crack spacing is consistent with a mechanism of internal heating involving the frictional sliding of fibers (as discussed in the next section, the area enclosed by the stress-strain hysteresis loops, which is proportional to the energy dissipation per cycle, also increases as the mean crack spacing is decreased). Although there was no appreciable difference in mean crack spacing for the prefatigue experiments conducted at peak stresses of 200 and $220 \mathrm{MPa}$, a larger temperature rise was observed after prefatigue at $220 \mathrm{MPa}$ (Fig. 14(A)). This further temperature rise is attributed to the additional debonding and fiber fractures which would be present after prefatigue at $220 \mathrm{MPa}$.

After completion of the experiments described above, and using the same specimen, additional information regarding the stress range and frequency dependence of frictional heating was obtained by comparing, at a crack spacing of $181 \mu \mathrm{m}$, the magnitude of the temperature rise which occurred at peak

${ }^{\ddagger}$ The mean crack spacing decreased from 184 to $181 \mu \mathrm{m}$. In view of the error in measuring crack spacing $( \pm 2 \mu \mathrm{m})$, this small difference is not considered experimentally significant.

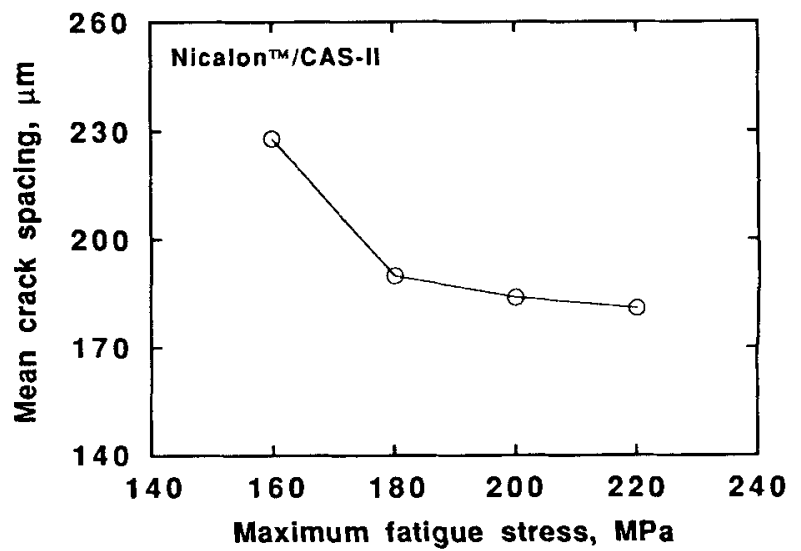

Fig. 12. Matrix crack spacing vs maximum fatigue stress. At each stress, fatigue was conducted for 50000 cycles at a frequency of $25 \mathrm{~Hz}$ and a minimum stress of $10 \mathrm{MPa}$ (see Fig. 11). 


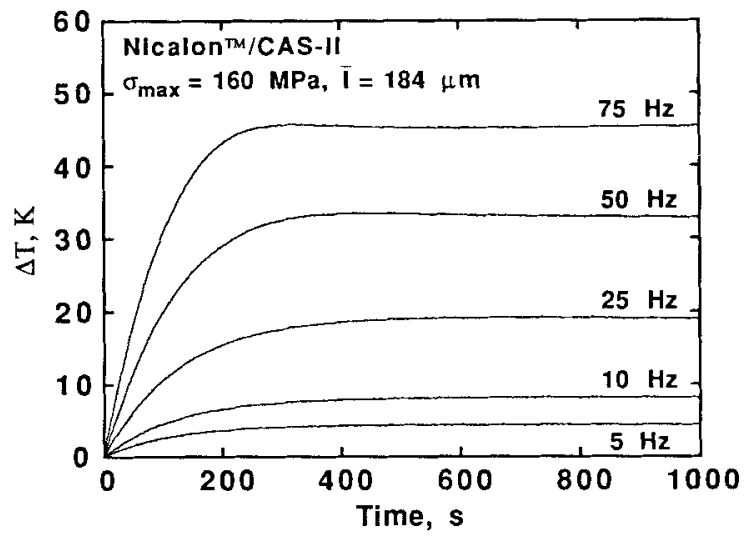

Fig. 13. Typical temperature rise curves obtained from fatigue experiments conducted at loading frequencies of 5 to $75 \mathrm{~Hz}$ between fixed stress limits of 160 and $10 \mathrm{MPa}$. The specimen was previously fatigued at $25 \mathrm{~Hz}$ for 50000 cycles between stress limits of 200 and $10 \mathrm{MPa}$; this provided an average matrix cracking spacing of $184 \mu \mathrm{m}$.

stresses of 160 and $220 \mathrm{MPa}$ (see Fig. 14(B)). At a peak stress of $220 \mathrm{MPa}$ the temperature rise was substantial, exceeding $100 \mathrm{~K}$ at a loading frequency of $75 \mathrm{~Hz}$. Examination of surface replicas taken before and after the experiment conducted at $220 \mathrm{MPa}$ showed no change in crack spacing.

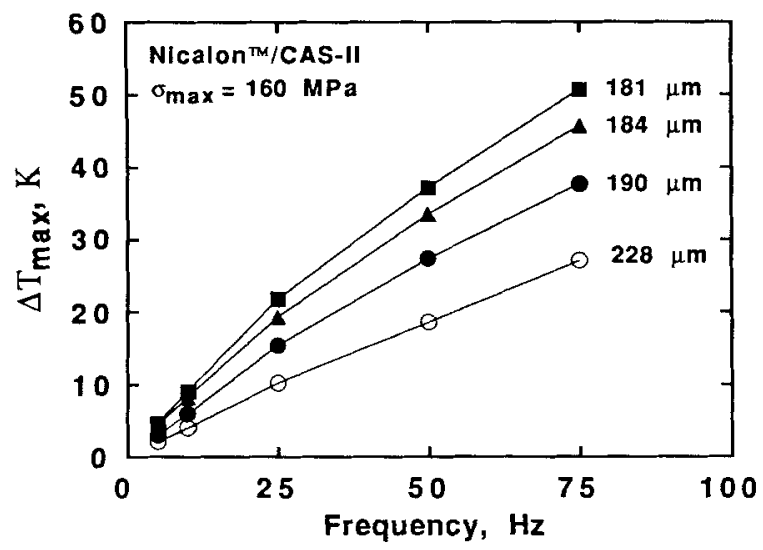

(A)

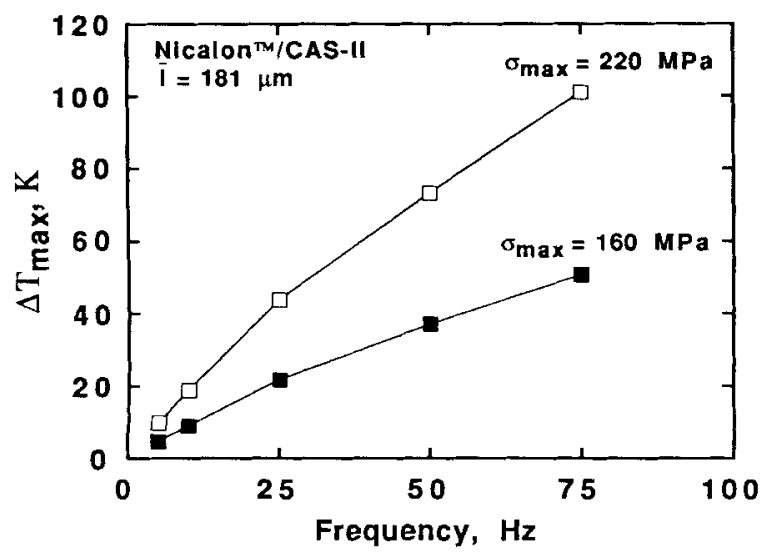

(B)

Fig. 14. (A) Influence of average matrix crack spacing and loading frequency on maximum temperature rise at a fixed stress range (the experiments were conducted between fixed stress limits of 160 and $10 \mathrm{MPa}$; see Fig. 11). (B) Influence of stress range and loading frequency on maximum temperature rise at a constant crack spacing (for both fatigue stresses the minimum cycle stress was $10 \mathrm{MPa}$ ).

\section{(5) Influence of Long-Duration Fatigue on Temperature Rise}

During the tension-tension fatigue of $0^{\circ} / 90^{\circ} \mathrm{C} / \mathrm{SiC}$ composites produced by chemical vapor infiltration, Holmes and Shulcr ${ }^{10}$ observed an initial peak in specimen temperature, followed by a gradual decay. In parallel with the temperature decay, a slight increase in the average stress-strain modulus occurred. The initial decay in specimen temperature was postulated to be the result of a decrease in interfacial shear stress caused by wear damage along the fiber/matrix interface. To detcrmine if a similar temperature decay occurs in unidirectional Nicalon/CAS-II composites, a virgin specimen was subjected to continuous $25-\mathrm{Hz}$ fatigue between fixed stress limits of 180 and $10 \mathrm{MPa}$. As shown in Figs. 15(A) and (B), the tempcrature rise reached an initial peak within the first $30000 \mathrm{cy}-$ cles, followed by a sharp decrease of approximately $1 \mathrm{~K}$ and a gradual recovery in temperature which persisted until approximately 750000 cycles. Beyond 750000 cycles the temperature rise slowly decayed. A sharp increase in temperature rise was observed immediately prior to specimen failure.

The changes in specimen temperature were roughly paralleled by changes which occur in the amount of stress-strain hysteresis. As shown in Fig. 16, the hysteresis slowly increases toward an initial maximum at approximately 50000 cycles. For the stress limits and loading frequency used in the experiment, the crack spacing stabilized within approximately 20000 cycles (sce Fig. 8); thus, the additional strain ratchetting which occurred between 20000 and 500100 cycles is attributed to further interfacial debonding. Although further strain ratchetting occurred between 50000 and $3.18 \times 10^{6} \mathrm{cy}-$

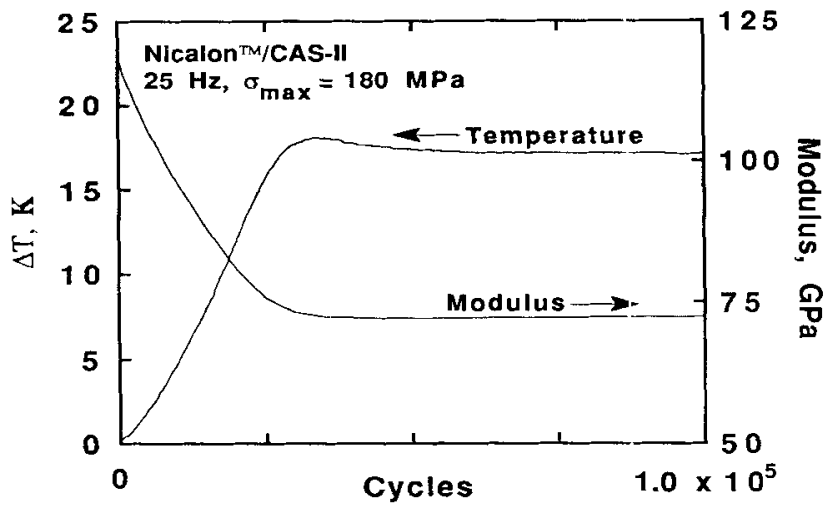

(A)

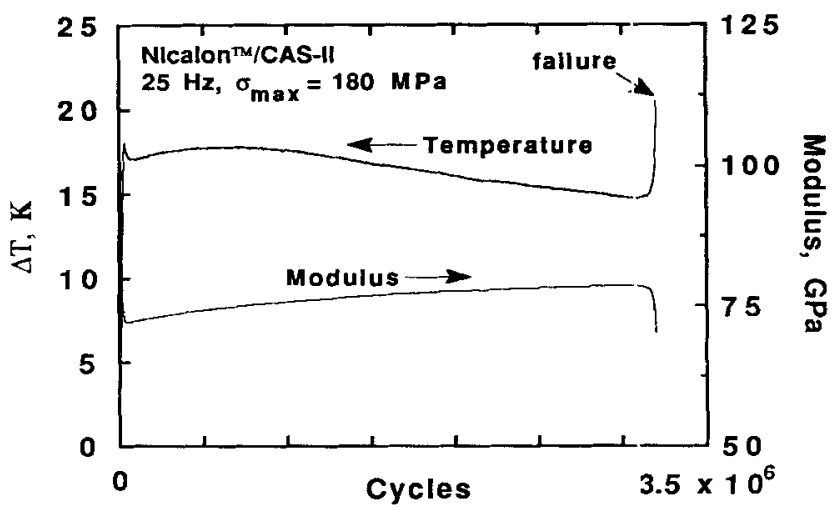

(B)

Fig. 15. Influence of long-duration cyclic loading on temperature rise and cyclic stress-strain modulus. The experiment was conducted at a loading frequency of $25 \mathrm{~Hz}$ between fixed stress limits of 180 and $10 \mathrm{MPa}$. (A) The modulus rapidly decreased within the first 30000 cycles of fatigue. (B) With further fatigue, a partial recovery in modulus and gradual decay in temperature was found. Failure occurred at $3.21 \times 10^{6}$ cycles. 


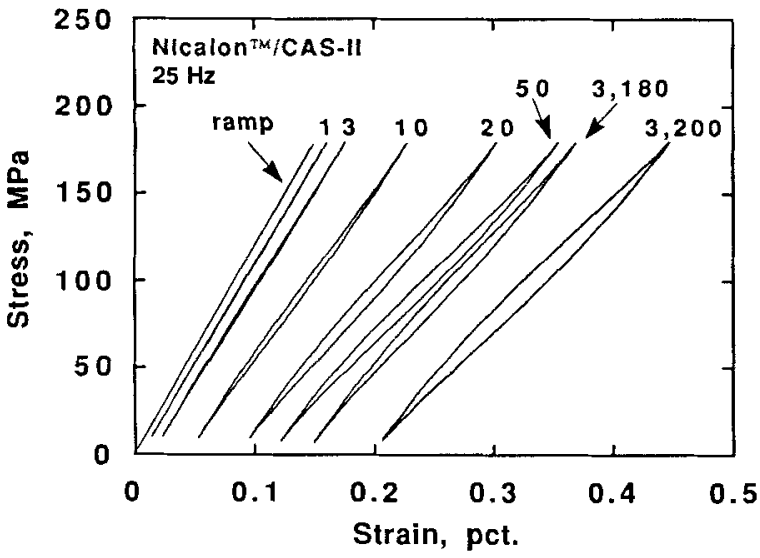

Fig. 16. Change in hysteresis behavior during the long-duration fatigue of unidirectional Nicalon/CAS-II. The experiment was conducted at $25 \mathrm{~Hz}$ between fixed stress limits of 180 and $10 \mathrm{MPa}$. The numbers above each curve give the fatigue cycles in thousands. Specimen failure occurred at approximately $3.21 \times 10^{6}$ cycles.

cles, the extent of hysteresis decreased by less than $5 \%$. A large increase in hysteresis occurred immediately prior to specimen failure, which occurred at approximately $3.21 \times$ $10^{6}$ cycles.

The average cyclic stress-strain modulus exhibited an initially rapid decay - from an initial value of $120 \mathrm{GPa}$ to approximately $70 \mathrm{GPa}$ after 30000 fatigue cycles (Figs. 15(A) and (B)). This rapid modulus decay is attributed to the formation of matrix cracks and debonding along the fiber/matrix interface. Beyond approximately 100000 cycles, the modulus slowly recovered, to roughly $80 \mathrm{MPa}$ immediately prior to specimen failure. Under load-controlled fatigue, an increase in specimen modulus produces a proportional decrease in strain amplitude ( $\Delta \sigma \propto E_{\mathrm{c}} \Delta \varepsilon$ ). Noting that the amount of heating is qualitatively related to strain range (see Fig. 9(B)), the modulus recovery which occurred during cyclic loading appcars to be partially responsible for the gradual decay in temperature observed beyond 750000 fatigue cycles. As discussed in a later section, the modulus recovery is attributed to a partial recovery in frictional shear stress.

\section{(6) Comments on Damping Behavior and Cyclic \\ Stress-Strain Behavior}

For the experiments described earlier, the maximum temperature rise showed an approximately linear dependence on loading frequency within the range of 5 to $25 \mathrm{~Hz}$. At higher frequencies, the temperature rise was significantly less than that predicted by a linear extrapolation of data obtained at frequencies of $25 \mathrm{~Hz}$ and lower. Two possible mechanisms for this trend are the following: (1) differential thermal expansion between the fibcr and the matrix causes a slight reduction in interfacial shear stress and (2) other modes of energy dissipation were present at frequencies of $50 \mathrm{~Hz}$ and higher. The first possibility is consistent with the thermal expansion mismatch between Nicalon fibers and the CAS matrix: $\alpha_{\text {Nicaton }} \approx 4 \times 10^{-6}{ }^{\circ} \mathrm{C}^{-1}$ and $\alpha_{\text {CAS }} \approx 5 \times 10^{-6}{ }^{\circ} \mathrm{C}^{-1} .{ }^{17}$ Thus, for Nicalon/CAS-II composites, a bulk temperature rise would cause a decrease in normal stress and, therefore, shear stress across the interface. The later possibility is suggested by cxamination of Figs. 17(A) and (B), which show that a significant change in the cyclic stress-strain behavior occurs at loading frequencies of 50 and $75 \mathrm{~Hz}$. Recent experiments, conducted using a much stiffer loading frame with a resonant frequency above $300 \mathrm{~Hz},{ }^{\S}$ showed no appreciable distortion of the hysteresis loops when similar specimens were tested at frequencies up to $150 \mathrm{~Hz}$. Thus, the change in stress-strain

\footnotetext{
sAn MTS Servohydraulic Model 331 load-frame was used in these experiments. ${ }^{20}$
}

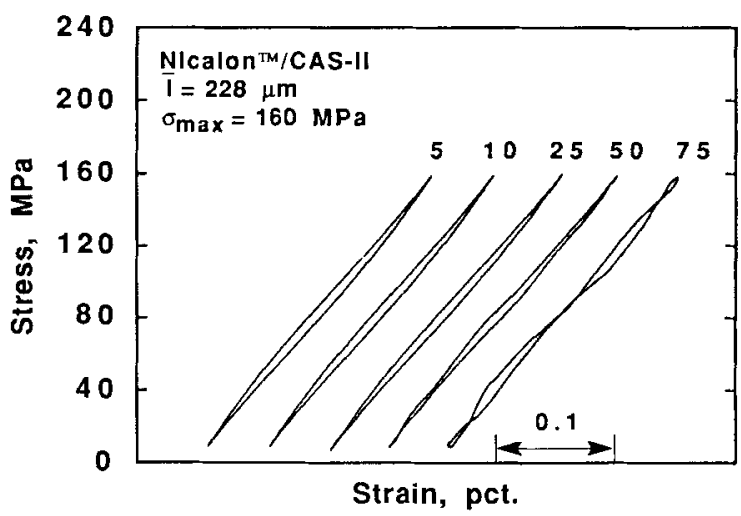

(A)

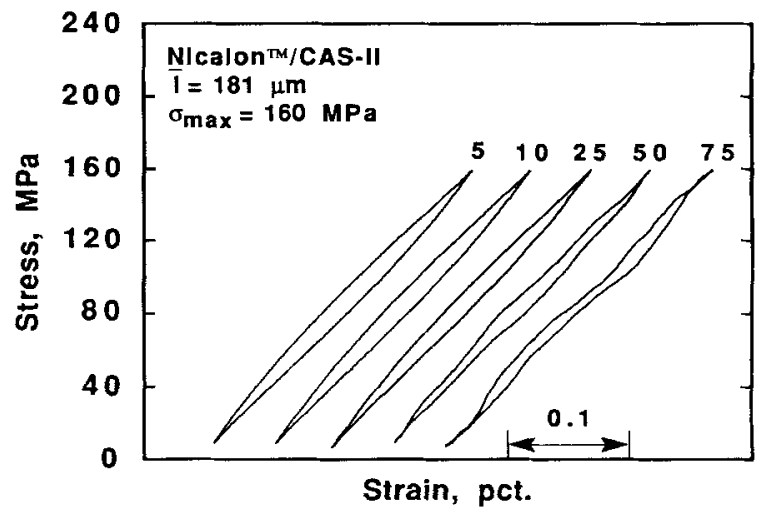

(B)

Fig. 17. Influence of loading frequency on the cyclic stress-strain response of $[0]_{16}-$ Nicalon/CAS-II. The hysteresis loops were obtained at the end of each 1000-s test. The numbers above each curve correspond to the sinusoidal loading frequency in $\mathrm{Hz}$. The distortion of the hysteresis curves at 50 and $75 \mathrm{~Hz}$ is attributed to compliance of the load frame.

behavior at 50 and $75 \mathrm{~Hz}$ appears to be caused by compliance of the loading frame, rather than a change in the intrinsic damping behavior of the composite. These experiments also indicate that the interfacial shear stress decreases at loading frequencies above $50 \mathrm{~Hz} .^{18}$

\section{(7) Influence of Loading Frequency on Interfacial} Frictional Shear Stress

Cho et al. ${ }^{19}$ recently developed an approach whereby the frictional shcar stress which is present during the cyclic loading of fiber-reinforced ceramics can be estimated by analysis of frictional heating data. The approach involves performing an energy balance to relate the energy dissipated through the frictional slip of fibers to the heat loss from a fatigue specimen to its surroundings. Assuming that the fibers undergo partial frictional slip, the work performed in the frictional slip of fibers, $\mathrm{d} w_{\text {fric }} / \mathrm{d} t$, is given in terms of the loading frequency $f$, applied stress range, $\Delta \sigma$, average matrix crack spacing, $\bar{l}$, and dynamic frictional shear stress, $\tau_{\mathrm{d}}$ :

$$
\frac{\mathrm{d} w_{\text {fric }}}{\mathrm{d} t}=\frac{f d_{\mathrm{f}} \Delta \sigma^{3}}{24 E_{\mathrm{l}} \overline{\bar{l}}_{\mathrm{d}}}\left[\frac{\left(1-v_{\mathrm{f}}\right) E_{\mathrm{m}}}{v_{\mathrm{f}} E_{\mathrm{c}}}\right]^{2}
$$

where $E_{\mathrm{f}}, E_{\mathrm{m}}$, and $E_{\mathrm{c}}$ are the initial tensile moduli of the fibers, matrix, and composite, respectively, and $v_{\mathrm{f}}$ and $d_{\mathrm{f}}$ are the fiber volume fraction and fiber diameter, respectively. Neglecting other modes of mechanical energy loss, the energy dissipated as frictional work, $\mathrm{d} w_{\text {Iric }} / \mathrm{d} t$, equals the rate of heat loss to the surroundings. The rate of heat loss can be determined by summing the convective, radiative, and conductive 
heat losses from the fatigue specimen. Alternatively, the heat loss can be obtained directly from the cyclic stress-strain hysteresis curves obtained during a fatigue test (the energy dissipation per cycle is determined by calculating the area enclosed by a cyclic stress-strain curve and multiplying by the loading frequency).

Using Eq. (1), and the temperature rise data given in Fig. 14(A), $\tau_{\mathrm{d}}$ was determined as a function of loading frequency and mean crack spacing. As shown in Fig. 18, within the range of 5 to $25 \mathrm{~Hz}$ the interfacial shear is approximately constant. Higher-frequency data were not considered since machine compliance caused distortion of the hysteresis curves at 50 and $75 \mathrm{~Hz}$. The calculated interfacial shear stress shows a slight dependence on mean crack spacing, ranging from approximately $6 \mathrm{MPa}$ at $228 \mu \mathrm{m}$ to $3 \mathrm{MPa}$ at 184 and $181 \mu \mathrm{m}$. Noting that the crack spacing was changed by sequentially increasing the maximum fatigue stress, the apparent dependence of interfacial shear stress on crack spacing is most likely a consequence of additional microstructural damage which occurred during prefatigue at the higher peak st ress levels. The extent of interfacial debonding and number fiber fractures would increase with an increase in fatigue stress (the influence of fractured fibers on energy dissipation during fatiguc was not included in the analysis used to determine $\tau_{d}$ ).

\section{(8) Influence of Long-Duration Cyclic Loading on}

\section{Interfacial Shear Stres.}

The change in interfacial shear stress was determined for the long-duration fatigue experiment which was conducted for $3.21 \times 10^{6}$ cycles between stress limits of 180 and $10 \mathrm{MPa}$. For comparison, the interfacial shear stress was calculated using both temperature rise data (Figs. 15(A) and (B)) and the stress-strain hysteresis curves (Fig. 16). When using temperature rise data, the energy balance given by Eq. (1) is valid only after the mean crack spacing and gage-section temperature have stabilized. However, using hysteresis data, Eq. (1) can be used so long as the mean crack spacing corresponding to a particular hysteresis curve is known. From Fig. 15(B), the

The rate of heat loss per unit volume, $\mathrm{d} q / \mathrm{d} t$, is given in terms of the surface temperature of the specimen $T_{\mathrm{s}}$, air temperature $T_{\mathrm{a}}$, convective heat transfer coefficient $h$, emissivity $\varepsilon$, and the thermal conductivity of the composite parallel to the fibers $k$.

$$
\frac{\mathrm{d} q}{\mathrm{~d} t}=\left[h\left(T_{\mathrm{s}}-T_{\mathrm{i}}\right)+\varepsilon \beta\left(T_{\mathrm{s}}^{4}-T_{\mathrm{i}}^{\ddagger}\right)\right] \frac{A_{\mathrm{sutit}}}{V}+\frac{2 k A_{\text {cond }}}{V}\left[\frac{\Delta T}{\Delta z}\right]_{\mathrm{ixial}}
$$

where $\beta$ is the Stefan-Boltzmann constant $\left(5.67 \times 10^{8} \mathrm{~W} /\left(\mathrm{m}^{2} \cdot \mathrm{K}^{4}\right)\right)$, $[\Delta T / \Delta z]_{\text {axial }}$ is the axial temperature gradient across the end of the specimen gage section, and $A_{\text {surf }}$ and $A_{\text {cond }}$ are the surface area and the cross section of the gage section, respectively.

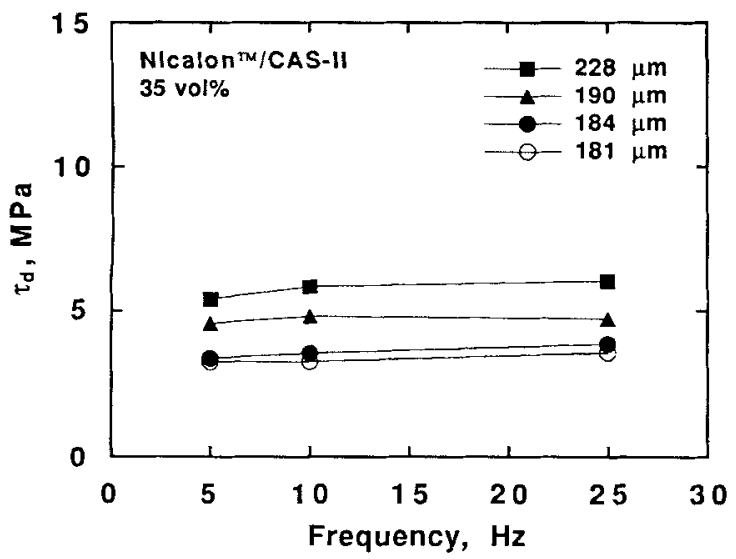

Fig. 18. Influence of loading frequency and mean crack spacing on dynamic interfacial shear stress, $\tau_{d}$. The temperature rise data given in Fig. 14(A) were used in the analysis. temperature rise stabilized within approximately 30000 cycles. ${ }^{* *}$ The change in matrix crack spelling was not monitored during the long-duration fatigue experiment. However, for the particular loading history used, it was oreviously determined that the mean crack spacing in a virgin specimen reaches a plateau within approximately 20000 cycles (see Fig. 8). With this knowledge, the matrix crack spacing present during the long-duration fatigue experiment was estimated from surface replicas taken after specimen f́cilure, which occurred at approximately $3.21 \times 10^{6}$ cycles (the: presence of debris along the crack faces, which prevented complete crack closure after failure, allowed the matrix cracks to be clearly identified in the surface replicas). The replicas were obtained from regions of the gage section which were remote to the final fracture location; the mean crack spacing was $209 \mu \mathrm{m}$. This crack spacing is $11 \mu \mathrm{m}$ larger than that rneasured for the specimen used in the constant stress-range experiments (this specimen was prefatigued at $180 \mathrm{MPa}$; see Fig. 8), and $19 \mu \mathrm{m}$ larger than that measured after the specinien used in the variable-frequency experiments was prefatigued at $180 \mathrm{MPa}$ (see Fig. 12). These differences in crack spacing are attributed to in homogeneitics in the fiber distribution present in the billet from which the test specimens were obtained.

As shown in Figs. 19(A) and (B) the interfacial shear stress undergoes an initially rapid decrease, from over $20 \mathrm{MPa}$ to approximately $5 \mathrm{MPa}$ at 25000 cycles, after which a gradual recovery to approximately $7 \mathrm{MPa}$ occurs prior to specimen failure at $3.21 \times 10^{6}$ cycles (note that these interfacial shear stress values are based upon calculations made using the hysteresis data). The initial decrease in interfacial shear stress is attributed to a rapid wear process that occurs along interfacial slip zones through the repeated frictional siding of fibers. Jero and Kerans ${ }^{21}$ and Mackin et al. ${ }^{22}$ have proposed that interfacial wear is a likcly mechanism of fatigue camage in fiberrcinforced composites. It has been suggested that surface roughness along the fiber/matrix interface controls the rate of interfacial wear during the cyclic loading of ceramic-matrix composites. ${ }^{21}$ The decrease in interfacial shear stress which was found in the present investigation provides clear experimental evidence for a wear mechanism during the initial stages of fatigue loading.

As mentioned earlier, both the interfacial shear stress and cyclic stress-strain modulus showed a partial recovery during long-duration fatigue. An increase in interfacial shear stress from 5 to $7 \mathrm{MPa}$ would increase the average modulus by approximately $8 \mathrm{GPa}$, in good agreement with the $6.5-\mathrm{GPa}$ recovery in modulus which was experimentally observed. Although speculative at this time, the partial recovery in interfacial shear stress which occurs during long-duration fatigue may be the result of time-dependent interaction with humidity in the test environment. This speculation is based upon results from fiber-pushout experiments conducted by Strevell and $\mathrm{Jero}^{23}$ which indicate that after initial fiber debonding the frictional shear stress in SCS-6/borosilicate glass composites increased upon subsequent exposure of the composites to humid environments.

\section{(9) Implications of Frictional Heating for the Use and Microstructural Design of Ceramic-Matrix Composites}

Certain results obtained from this study have important implications regarding the use and microstructural design of ceramic-matrix composites:

(1) The microstructures that impart high toughness to ccramic-matrix composites (relatively weak interfacial bond strength and generous fiber pullout lengths) will be the most susccptible to frictional heating. Frictional heating will also

**For a given composite system the rate at which the temperature rise stabilizes depends upon the applicd stress range and prior loading history of the specimen. For prefatigued specimens, the temperature rise can stabilize in as few as 5000 cycles (sce Fig. 13). 


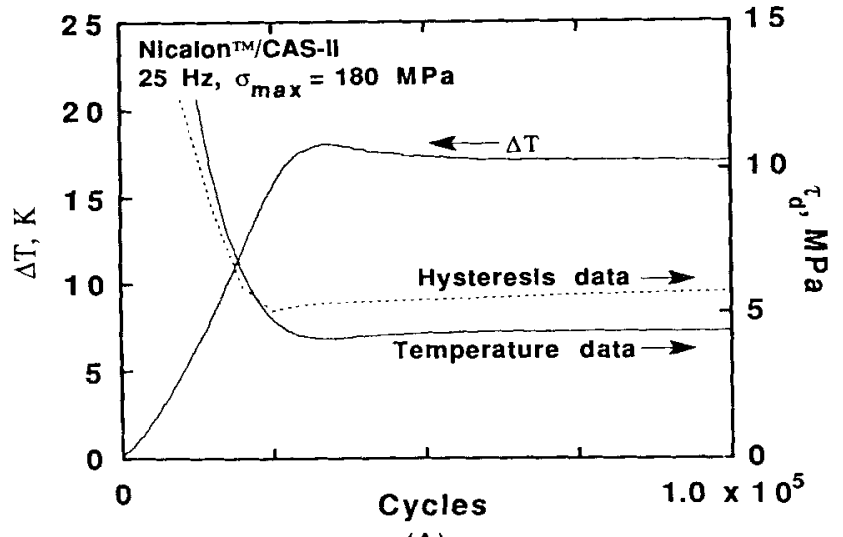

(A)

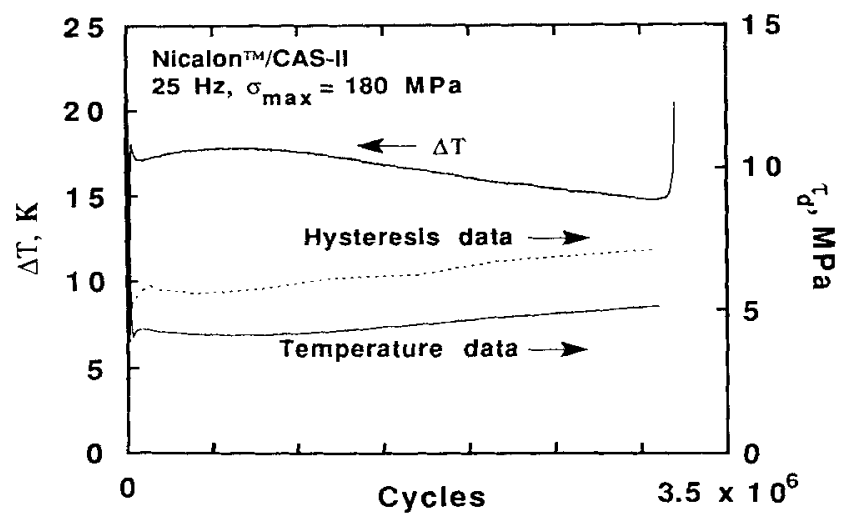

(B)

Fig. 19. Change in interfacial shear during long-duration cyclic loading between fixed stress limits of 180 and $10 \mathrm{MPa}$. For comparison, the interfacial shear was calculated using the temperature rise data given in Fig. 15 and stress-strain hysteresis data (several of the hysteresis curves are shown in Fig. 16). Specimen failure occurred at $3.21 \times 10^{6}$ cycles.

be influenced by such microstructural parameters as the type of fiber coating and the temperature dependence of mismatch in thermal expansion coefficients between the fiber and the matrix.

(2) Fatigue loading can cause a rapid decreasc in interfacial shear stress during the initial stages of fatigue. It is expected that the rate of decrease of interfacial shear stress will be influenced by such parameters as ambient temperature and loading frequency, both of which will influence the rate of interfacial wear. The decrease in interfacial shear stress found during the initial stages of fatigue loading will result in a cycle dependence of such properties as toughness and strength. Although the interfacial shear stress was found to be approximately constant over the range of 5 to $25 \mathrm{~Hz}$, additional work is required to determine if this trend will persist at higher loading frequencies where the change in differential thermal expansion would be expected to influence the frictional shear stress.

(3) As a consequence of differential thermal expansion between the fiber and the matrix, it is expected that the mechanical behavior and thermophysical properties of fiberreinforced ceramics will be influenced by loading frequency. This frequency dependence of properties will need to be accounted for in the design of structures and components. Since the extent of frictional heating will be influenced by many variables, including fiber volume fraction and layup, interfacial coatings, loading history and operating temperature, extensive experimental testing will be required to quantify the changes in properties which occur during fatigue.

(4) The correlation of frictional heating with matrix cracking and fiber debonding raises the interesting possibility that temperature rise information can be used to assess the initial damage state of ceramic composite panels or components. Monitoring temperature rise may also be a feasible method for determining the integrity and evolving damage state of structural components.

Finally, it should be mentioned that not all ceramic composites undergo internal heating of the magnitude observed in Nicalon/CAS-II and $\mathrm{C}_{\mathrm{f}} / \mathrm{SiC}^{\mathrm{Ii}}$ composites. For example, unpublished work by the authors has shown that cross-ply Nicalon/SiC composites processed by chemical vapor infiltration exhibit only minimal frictional heating during tensiontension fatigue loading (at a peak stress of $160 \mathrm{MPa}$ the temperature rise was typically less than $5 \mathrm{~K}$ at loading frequencies up to $75 \mathrm{~Hz}$ ).

\section{Conclusions}

Based upon the results obtained from tension-tension fatigue experiments performed in air at ambient temperature, the following conclusions can be made regarding frictional heating and dynamic interfacial shear stress in 16-ply unidirectional Nicalon/CAS-II composites with 35 vol\% fibers:

(1) The onset of frictional heating during cyclic loading coincides with the initiation of matrix cracking. Frictional heating and matrix cracking began at a peak stress of $120 \mathrm{MPa}$, which is approximately $50 \%$ below the initial monotonic proportional limit strength of the composite. This result indicates that fatigue damage in fiber-reinforced ceramics can occur at stress levels well below the monotonic proportional limit. This early fatigue damage has important implications regarding the use of these composites in high-temperature oxidizing environments.

(2) For a constant loading frequency and matrix crack spacing, the maximum temperature rise exhibits an approximately linear dependence on stress range or strain range. Increasing the stress range by $20 \mathrm{MPa}$ resulted in an average temperature increase of approximately $3.2 \mathrm{~K}$. For a fixed stress range, the temperature rise showed only a weak dependence on maximum fatigue stress. For example, at a stress range of $90 \mathrm{MPa}$, a change in peak stress from 100 to $180 \mathrm{MPa}$ resulted in less than a $1 \mathrm{~K}$ change in specimen temperature. These results suggest that the extent of internal heating is controlled primarily by the relative sliding distance of fibers within the matrix.

(3) For a given peak fatigue stress and stress range, the extent of frictional heating increases as the average matrix crack spacing decreases. At a loading frequency of $75 \mathrm{~Hz}$ and pcak stress of $160 \mathrm{MPa}(\Delta \sigma=150 \mathrm{MPa})$, the temperature rise ranged from $28 \mathrm{~K}$ at a crack spacing of $228 \mu \mathrm{m}$ to approximately $50 \mathrm{~K}$ at a crack spacing of $181 \mu \mathrm{m}$. At a crack spacing of $181 \mu \mathrm{m}$, the temperature rise exceeded $100 \mathrm{~K}$ at a peak stress of $220 \mathrm{MPa}(\Delta \sigma=210 \mathrm{MPa})$.

(4) The frictional shear stress along the fiber/matrix interface undergoes a significant reduction during the initial stages of fatigue. During long-duration fatigue at a loading frequency of $25 \mathrm{~Hz}$ and peak stress of $180 \mathrm{MPa}$, the dynamic interfacial shear stress showed an initially rapid decrease in the first 25000 cycles (from approximately 20 to $5 \mathrm{MPa}$ ), followed, after several million cycles, by a partial recovery to about $7 \mathrm{MPa}$. In parallel with the increase in interfacial shear stress, a partial recovery in the cyclic stress--strain modulus was observed. The magnitude of the modulus increase was consistent with analytical predictions which were based upon the observed increase in interfacial shear stress.

(5) A gradual decay in temperature rise was observed during long-duration fatigue loading. The temperature rise ( $\left.T-T_{\text {anbient }}\right)$ decreased from a maximum of approximately $18 \mathrm{~K}$ at 30000 cycles to $15 \mathrm{~K}$ after $3.16 \times 10^{6}$ cycles. This decrease in temperature is attributed in part to the modulus recovery which occurs during cyclic loading; under load- 
controlled fatigue, a modulus increase causes a proportional reduction in strain range $\left(\Delta \varepsilon=\Delta \sigma / E_{c}\right)$ and, hence, a reduction in the frictional sliding distance of fibers. The interfacial shear stress was not significantly influenced by loading frequency; for a given crack spacing, there was less than a $1-\mathrm{MPa}$ change in shear stress for loading frequencies between 5 and $25 \mathrm{~Hz}$.

(6) The occurrence of frictional heating and the cycle dependent change in frictional shear stress have important implications regarding the role of the fiber/matrix interface in fatigue and the use of ceramic composites in applications involving fatigue loading. In particular, differential thermal expansion between the fiber and the matrix during cyclic loading may result in a frequency dependence of properties which are influenced by the degree of contact between the fiber and the matrix, such as interfacial wear and mechanical properties such as toughness, damping, and fatigue life. Thermophysical properties such as thermal conductivity are also expected to be influenced by loading frequency.

\section{References}

${ }^{1}$ D. B. Marshall and A. G. Evans, "Failure Mechanisms in Ceramic-Fiber/ Ceramic-Matrix Composites," J. Am. Ceram. Soc, 68 [5] 225-31 (1985).

${ }^{2}$ E. Minford and K. M. Prewo, "Fatigue of Silicon Carbide Reinforced Lithium Aluminosilicate Glass-Ceramics;" pp. 561-70 in Tailoring Multiphase and Composite Ceramics. Edited by C. G. Patano and R. E. Messing. Plenum Publishing Corp., New York, 1986.

${ }^{3}$ K. M. Prewo, "Fatigue and Stress Rupture of Silicon Carbide Fibre-Reinforced Glass-Ceramics," J. Mater. Sci., 22, 2695-701 (1987).

${ }^{4}$ J.W. Holmes, "Influence of Stress-Ratio on the Elevated Temperature Fatigue Life of a SiC Fiber-Reinforced $\mathrm{Si}_{3} \mathrm{~N}_{4}$ Composite," J. Am. Cerum. Soc., $74[7] 1639-45$ (1991).

S. Shuler and J.W. Holmes, "Influence of Frequency on the Rate of Damage Accumulation During Fatigue of C-Fiber SiC-Matrix Composites"; presented at the 15th Annual Conference on Ceramics and Advanced Composites, Cocoa Beach, FL, January 1990 (Paper No. 116-C-91F).

${ }^{6}$ D. B. Marshall and W. C. Oliver, "Measurement of Interfacial Mechanical Properties in Fiber-Reinforced Ceramic Composites," J. Am. Ceram. Soc., 70 [8] 542-48 (1987).
${ }^{7}$ B. N. Cox, "Interfacial Sliding near a Fibrous or Layered Composite During Thermal Cycling," Acta Metall. Mater., 38 [12] $2411-24$ (1990).

${ }^{r}$ R. M. McMeeking and A. G. Evans, "Matrix Fatigue Cracking in Fiber Composites," Mech. Mater., 9 217-27 (1990).

${ }^{9}$ T. Kotil, J.W. Holmes, and M. Comninou, "Origin of Hysteresis Observed During Fatigue of Ceramic Matrix Composites," $\triangle$ Am. Ceram. Soc. 73 [7] 1879-83 (1990).

10. W. Holmes and S. F. Shuler, "Temperature Rise Juring Fatigue of Fibre-Rcinforced Ceramics," J. Mater. Sci. Lett., 9 [11] 12010-91 (1990).

"J.W. Holmes and C. Cho, "Frictional Heating in a Fiber-Reinforced Ceramic Composite," J. Mater. Sci. Lett., 11, $41-44$ (1992).

12 J.W. Holmes, "A Technique for Tensile Fatigue and Creep Testing of Fiber-Reinforced Ceramics," J. Compos. Mater, in press.

${ }^{1 *}$ L. Butkus and L. Zawada, "Room Temperature Te xsile and Fatigue Properties of Silicon Carbide Fiber-Reinforced Ceranic Matrix Com posites"; presented at Aeromat '90, Long Beach, CA, May 21-24, 1990.

${ }^{14} \mathrm{~J}$. Aveston and A. Kelly, "Theory of Multiple Fracture of Fibrous Compsites," J. Mater. Sci., 8, 352-62 (1973).

${ }^{15}$ B. Budiansky, J.W. Hutchinson, and A. G. Evans, "Matrix Fracture in Fiber-Reinforced Ceramics," J. Mech. Phys. Solids, 34 [2] 167-89 (1986).

${ }^{1 n} \mathrm{C}$. Cho, J.W. Holmes, and J. R. Barber, "Distribution of Matrix Cracks in a Uniaxial Ceramic Composite," J. Am. Ceram. Soc., 75 [2] 316-24 (1992).

${ }^{17}$ P. Karandikar, R. Talreja, and T.-W. Chou, "Evolution of Damage and Mechanical Response of Ceramic Matrix Composites," submitted to J. Mater. Sci.

${ }^{18} \mathrm{C}$. Cho and J.W. Holmes, "Influence of Fatigue Loading and Test Fre quency on Interfacial Shear Stress in Fiber-Reinforced Cerc mics"; presented at the 16th Annual Conference on Composites and Advanced Ceramics, Cocoa Beach, FL, January 7-10, 1992 (Paper No. 50-C-92F).

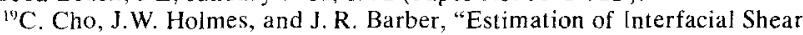
in Fiber-Reinforced Ceramics from Frictional Heating Measurements," J. Am. Ceram. Soc., 74 [11] 2802-808 (1991).

"V. Ramakrishnan, J.W. Holmes, and M. Comninou," High-Frequency Fatigue and Internal Heating in Fiber-Reinforced Ceramics"; presented at the 16th Annual Conference on Composites and Advanced Ceramics, Cocoa Beach, FL, January 7-10, 1992 (Paper No. 51-C-92F).

${ }_{21}$ P. D. Jero, R. J. Kerans, and T. A. Parthasarathy, "Effect of Interfacial Roughness on the Frictional Stress Measured Using Pushout Tests," J. Am. Ceram. Soc., 74 [11] 2793-801 (1991)

${ }^{22}$ T. J. Mackin, P. D. Warren, and A. G. Evans, "Fiber Pushout of a Fatigued Specimen"; presented at the 93rd Annual Meeting of the American Ceramic Society, Cincinnati, OH, April 30, 1991 (Paper No. 54-SVI-91).

${ }^{23}$ R. J. Strevell and P.D. Jero, "Effect of Moisture on the Fiber/Matrix Bond Strength and Sliding Friction in a Glass Matrix Compcsite"; presented at the 93rd Annual Meeting of the American Ceramic Society, Cincinnati, $\mathrm{OH}$, April 30, 1991 (Paper No. 64-SV1-91). 